\title{
Hereditary Angioedema in Pregnancy and Management without Recombinant Human C1-INH
}

\author{
Natália Paseto Pilati' ${ }^{1}$, Maria Alexandrina Zanatta ${ }^{1}$, Daniele Camila Maltauro ${ }^{1}$, \\ Gabrielle Behenck ${ }^{1}$, Edimárlei Gonsales Valério ${ }^{1,2}$, Fernanda Oliveira Castilhos ${ }^{1,3}$, \\ Eduardo Vettorazzi-Stuczynski ${ }^{3}$, Daniela Vanessa Vettori ${ }^{1,2}$, Janete Vettorazzi ${ }^{1,2^{*}}$ \\ ${ }^{1}$ Postgraduation Program in Health Sciences: Gynecology and Obstetrics (PPGGO), Faculdade de Medicina (FAMED), \\ Universidade Federal do Rio Grande do Sul (UFRGS), Porto Alegre, Rio Grande do Sul, Brazil \\ ${ }^{2}$ Service of Gynecology, Hospital de Clinicas de Porto Alegre, Porto Alegre, Brazil \\ ${ }^{3}$ Hospital Geral de Caxias do Sul e Faculdade de Medicina da Universidade de Caxias do Sul, Caxias do Sul, Brazil \\ Email: *jvettorazzi@hcpa.edu.br
}

How to cite this paper: Pilati, N.P., Zanatta, M.A., Maltauro, D.C., Behenck, G., Valério, E.G., Castilhos, F.O., Vettorazzi-Stuczynski, E., Vettori, D.V. and Vettorazzi, J. (2021) Hereditary Angioedema in Pregnancy and Management without Recombinant Human C1-INH. Open Journal of Obstetrics and Gynecology, 11, 1470-1476.

https://doi.org/10.4236/ojog.2021.1111137

Received: October 4, 2021

Accepted: November 8, 2021

Published: November 11, 2021

Copyright $\odot 2021$ by author(s) and Scientific Research Publishing Inc. This work is licensed under the Creative Commons Attribution International License (CC BY 4.0).

http://creativecommons.org/licenses/by/4.0/

\begin{abstract}
A pregnant woman diagnosed with type 1 angioedema seeks care at a public hospital for planning the delivery. This report presents ways to prevent and manage an acute HAE crisis during childbirth and early postpartum without the availability of first-line medications, such as plasma-derived human C1-INH concentrate.
\end{abstract}

\section{Keywords}

Hereditary Angioedema (HAE), C1-Inhibitor, High-Risk Pregnancy, Prophylaxis

\section{Introduction}

Hereditary angioedema (HAE) is a rare autosomal dominant disease caused by a disorder of C1-inhibitor (C1-INH) [1], which regulates the generation of bradykinin, a vasodilator that increases capillary permeability [2]. HAE caused by C1-INH deficiency (HAE-C1-INH) is classified into two subtypes: type I, the most prevalent ( $85 \%$ of cases), is characterized by low levels of C1-INH; and type II has normal C1-INH levels, but impaired C1-INH function. Both subtypes are caused by mutations in the SERPING1 gene [2] [3].

HAE-C1-INH is characterized by recurrent and unpredictable attacks of subcutaneous and submucosal swelling. Skin lesions are typically well circumscribed, asymmetrical, non-pruritic, non-urticaria [1] [3] and last for 3 to 5 days 
[3]. Crisis may be preceded by prodromal symptoms such as: erythema marginatum, a macular rash similar to urticaria. Crises involving the gastrointestinal mucosa are also common and it can mimic an acute abdomen. Airway edema is less frequent, but more severe and it can result in death from asphyxia [1] [3].

Symptoms usually appear in childhood or adolescence and worsen after puberty [1] [3]. Women tend to have more severe symptoms [1] [2] [3] presumably due to increased estrogen exposure (endogenous and exogenous) [3]. The effect of gestation on HAE is variable, as aggravating or attenuating angioedema attacks [1] [2] [3], even for the same patient during different pregnancies [1] [3]. Czaller et al. reported that HAE attack frequency increased $48 \%$ in pregnancies, while $33 \%$ of pregnancies were associated with attenuation of clinical signs. $52 \%$ of crises during pregnancy occurred in the third trimester. Abdominal crises are the most common presentation of HAE during pregnancy [4].

\section{Case}

A 33-year-old caucasian woman, primiparous, with hereditary type I angioede$\mathrm{ma}$ and without other comorbidities or allergies.

She was diagnosed at 16 years old, after her mother tested positive for the disease. The first crisis happened when she was 18 years old. She had two episodes with airway involvement in her life; the last one at 30 years old. Started using danazol, a second line prophylaxi medication, every 6 months in 2016. In 2018, she added oxandrolone, also a second line prophylaxi medication, interspersing with Danazol every 6 months, with clinical control of the crisis. Both medications act suppressing pituitary output of follicle-stimulating hormone (FSH) and luteinizing hormone (LH) and reduce attacks associated with hereditary angioedema by increasing levels of $\mathrm{C} 4$ component of complement. As a side effect, she developed an androgenic hair pattern (Figure 1).

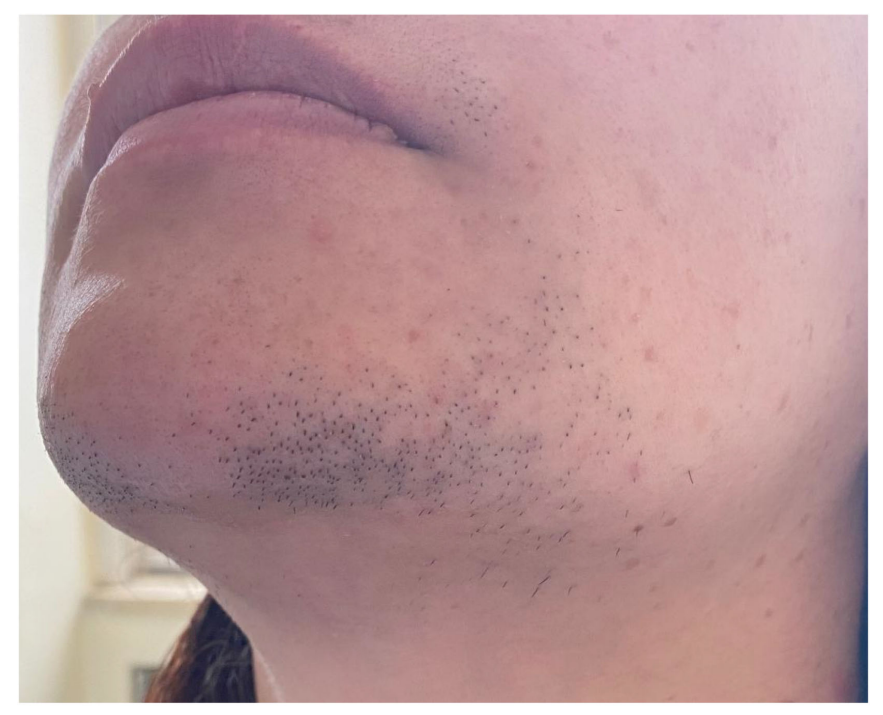

Figure 1. Androgenic hair pattern after long-term treatment with danazol and oxandrolone. 
Due to a desire to get pregnant, she suspended the medication, since Danazol and Oxandrolone are contraindicated in pregnancy due to a risk of virilization of the female fetus. During pregnancy, no medication was used until 30 weeks of gestational age. Due to light crises almost daily, with edema of hands and feet, she started the use of epsilon-aminocaproic acid $500 \mathrm{mg} /$ day prophylactically, an antifibrinolytic drug safe in pregnancy. The last crisis during the pregnancy was at 33 weeks of gestational age. She had uncomplicated prenatal care, except light crises of HAE as told.

At 37 weeks of gestational age, she was referred to a tertiary medical center for high-risk pregnancy prenatal care in order to plan the delivery with a multidisciplinary team: immunology, anesthesiology and obstetrics. On the second day in the hospital, spontaneous fetal membranes ruptured, initiating labor. Discussed with the patient and family, in addition to a multidisciplinary team, it was opted for vaginal birth.

The first prevention line for a crisis, Berinert (plasma-derived C1INH), was unavailable in the hospital. As a second line of prevention treatment, the hospital had fresh frozen plasma. Prophylactic tranexamic acid $750 \mathrm{mg}$ every 8 hours intravenously was started during labor as an alternative medication to prevent a crisis. Analgesia with spinal anesthesia + epidural catheter was performed to avoid crisis triggers. She was maintained with continuous fetal monitoring. Infusion of oxytocin was started to correct uterine dynamics.

After three hours of labor, there was the appearance of erythematous lesions, with raised borders, in breast, inframammary region and cardiotocography sites (Figure 2 and Figure 3). In addition, there was the appearance of edema in the lips and nose (Figure 4). No other signs of crisis were noticed during labor. Two units of fresh frozen plasma were transfunded during the expulsion period of labor. She had intrapartum fever, fetal tachycardia and leukocytosis after seven hour of membrane rupture. Treatment for chorioamnionitis was prescribed: amikacin and ampicillin. She had a vaginal delivery with second degree laceration.

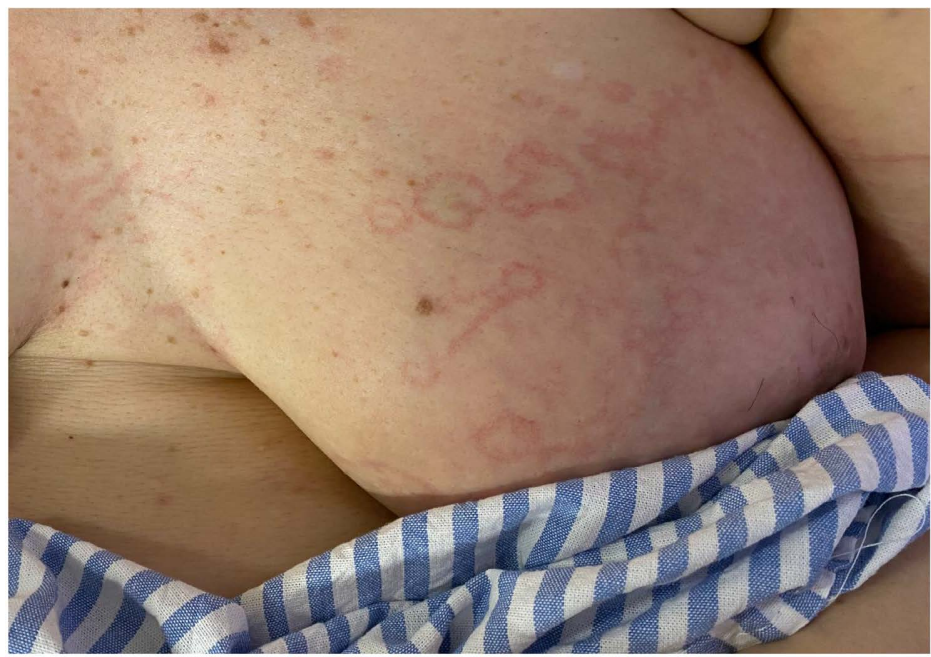

Figure 2. Erythematous lesions. 


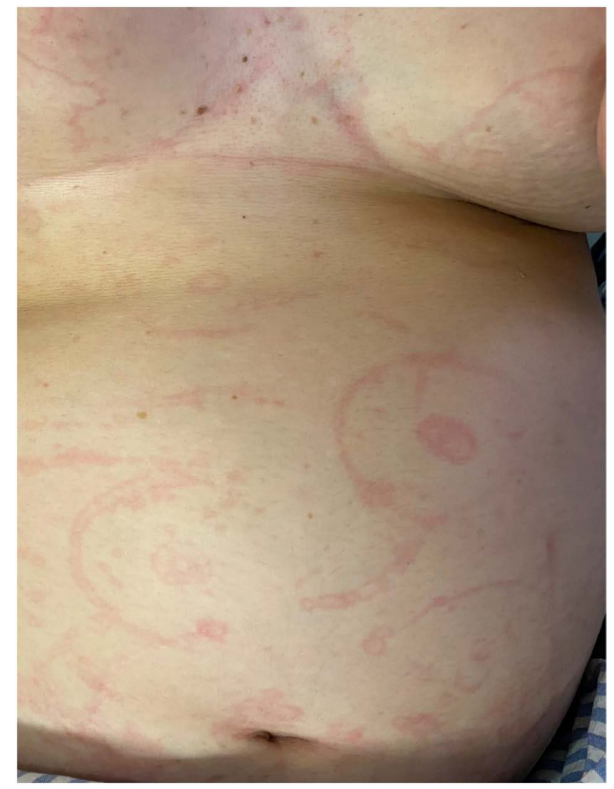

Figure 3. Erythematous lesions on the trunk, at insertion sites of intrapartum cardiotocography.

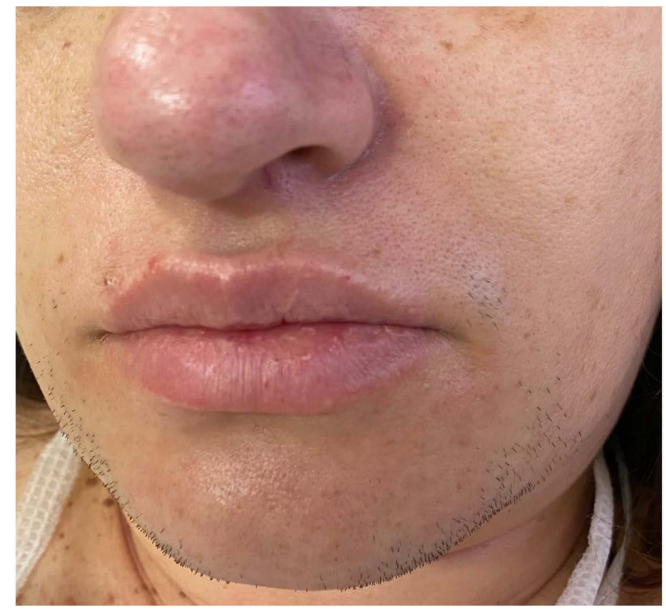

Figure 4. Upper lip and nose edema.

The newborn (NB) was female, weighing $2920 \mathrm{~g}$, with APGAR score of 7 and 9 in the 1st and 5th minutes.

Patient stayed under supervision in an obstetric center with intravenous tranexamic acid maintained for 48 hours after delivery. There was progressive improvement of the lesions within a few hours after fresh plasma administration. Patient didn't have any injury 24 hours after delivery. She underwent breast milk expression with mechanical breast pump to maintain milk production.

After 72 hours of tranexamic acid's suspension, the patient was released to breastfeed. She remains without any crisis after discontinuing the prophylaxis. Aware of the risks of breastfeeding and not using prophylaxis, she was advised in case of crises to use epsilon-aminocaproic acid $500 \mathrm{mg} /$ day and to suspend breastfeeding for the next 2 hours after using the medication (half-life time). She 
was discharged 7 days after delivery with the newborn, who will maintain a follow-up at genetic's service.

\section{Discussion}

Spontaneous vaginal delivery occurs in $80 \%-90 \%$ of births in HAE. The number of cesarean sections performed is similar to those in the overall population [5].

Despite suspicion that mechanical trauma involved in vaginal childbirth could trigger angioedema, there is no evidence to support this. Rarely vaginal deliveries cause an edematous attack (6\%). Those attacks appear immediately after or in the first 48 hours after delivery [5]. After delivery, the prevalence of vulva's angioedema is higher than it was before pregnancy [6].

Postpartum, some patients suffer a higher rate of edema episodes and/or abdominal attacks. During lactation, there is an increase in the number of episodes. Prolactin levels have been found to be associated with the number of abdominal episodes suffered by these patients [4].

\section{Management}

Plasma-derived human C1-INH concentrate: The first line of treatment during the pregnancy, postpartum and lactation period is plasma-derived human C1-INH concentrate. It is preferred for acute treatment, short-term prophylaxis, or long-term prophylaxis [7].

Antifibrinolytics Agents: Tranexamic acid is an option for mild edema attacks. However, there are no controlled studies of their effectiveness in treating acute crises. Even though it crosses the placenta, no mutagenic activity or harmful effects of tranexamic acid on the fetus have been reported and animal reproduction studies have shown no teratogenic effects. Tranexamic acid is not recommended during breast-feeding, because it can pass into breast milk [7].

Epsilon aminocaproic acid is effective in the prevention of angioedema attacks. The known side effects are thrombosis, muscle pain, extensive muscle necrosis, asthenia, weakness, abdominal pain, itching, nausea and dizziness. The standard dose is $1 \mathrm{~g}$ every 6 - 8 hours, and can be increased to $12 \mathrm{~g} /$ day divided into four doses. There are few data on it uses during pregnancy or lactation [5] [8].

Virally inactivated fresh frozen plasma (FFP): Fresh frozen plasma is an alternative in countries where pdhC1INH is not available and in cases where antifibrinolytics are contraindicated or ineffective [8]. When it is used for acute angioedema treatment, it has the possibility to worsen HAE symptoms. It happens because of supply substrates (factor XII, prekallikrein and high molecular weight kininogen) that can produce an increase in bradykinin before the supplied C1-INH has time to act.

Not enough data exist on the use of fresh frozen plasma for long-term prophylaxis during pregnancy [7], but it could be used if pdhC1INH is unavailable. In a review, FFP is an effective prophylactic agent before surgery and for treatment 
of acute HAE attacks without evidence of exacerbation or initiation of symptoms. The mean dosage of FFP infusion was $586 \mathrm{~mL}$. There was a definite improvement in symptoms 49 minutes after beginning FFP infusion. The remission time was 3.3 hours after FFP infusion [9].

Surgical procedures. In case of surgical procedures, there is no specific contraindication to general anesthetic medication. However, regional analgesia is preferable because it avoids the need to perform an endotracheal intubation, which can produce laryngeal edema. PdhC1INH is indicated $1-6$ hours prior to the procedure. If it is not available, virally inactivated fresh frozen plasma can be administered instead [7]. Thus, routine prophylaxis is not recommended before uncomplicated natural vaginal deliveries, although pdhC1INH should be immediately available in the delivery room [7].

In this case, we opted for the prophylactic use of tranexamic acid during labor and the use of FFP during the expulsive period of labor. This decision was taken because the patient shows skin lesions compatible with a mild acute crisis during labor. In addition, we consider the time-response symptom remission when using plasma, which should be taken into account to prevent severe acute crises.

\section{Breastfeeding}

Lactation might be associated with an increased number of angioedema attacks [10], particularly in women with predominantly abdominal symptoms [4]. Ceasing lactation itself might reduce attack frequency by causing a decrease in serum prolactin levels [11]. It is not known whether anabolic steroids are excreted into breast milk. Because of their potential side effects in children, it is recommended the ceasing breast-feeding before initiating anabolic steroids therapy.

It is not known if epsilon aminocaproic acid is excreted in breast milk. The half-life elimination of drugs is 1 to 2 hours and time to peak of oral use is 1, 2 hours. Because of that, we consider using epsilon aminocaproic acid if there is a crisis. However, it is pertinent ceasing breastfeeding for a few hours after medication administration [12].

\section{Conclusion}

There is a possibility of crisis management and prophylaxis during labor without first-line medications. In this case, the management was done with tranexamic acid and fresh plasma. There was no severe crisis during childbirth and immediate postpartum period. We highlighted the importance of referring these patients to a tertiary center as soon as possible and the availability for immediate fresh plasma.

\section{Conflicts of Interest}

The authors declare no conflicts of interest regarding the publication of this paper. 


\section{References}

[1] Busse, P.J. and Christiansen, S.C. (2020) Hereditary Angioedema. The New England Journal of Medicine, 382, 1136-1148. https://doi.org/10.1056/NEJMra1808012

[2] Betschel, S., Badiou, J., Binkley, K., et al. (2019) The International/Canadian Hereditary Angioedema Guideline. Allergy, Asthma \& Clinical Immunology, 15, Article Number 72.

[3] Busse, P.J., Christiansen, S.C., Riedl, M.A., et al. (2021) US HAEA Medical Advisory Board 2020 Guidelines for the Management of Hereditary Angioedema. The Journal of Allergy and Clinical Immunology. In Practice, 9, 132-150.e3. https://doi.org/10.1016/j.jaip.2020.08.046

[4] Czaller, I., Visy, B., Csuka, D., et al. (2010) The Natural History of Hereditary Angioedema and the Impact of Treatment with Human C1-Inhibitor Concentrate during Pregnancy: A Long-Term Survey. European Journal of Obstetrics \& Gynecology and Reproductive Biology, 152, 44-49.

https://doi.org/10.1016/j.ejogrb.2010.05.008

[5] Bouillet, L., Longhurst, H., Boccon-Gibod, I., et al. (2008) Disease Expression in Women with Hereditary Angioedema. Research General Gynecology, 199, 484.E1-484.E4. https://doi.org/10.1016/j.ajog.2008.04.034

[6] Caballero, T., Canabal, J., Rivero-Paparoni, D., et al. (2014) Management of Hereditary Angioedema in Pregnant Women: A Review. International Journal of Women's Health, 6, 839-848. https://doi.org/10.2147/IJWH.S46460

[7] Caballero, T., Farkas, H., Bouillet, L., et al. (2012) International Consensus and Practical Guidelines on the Gynecologic and Obstetric Management of Female Patients with Hereditary Angioedema Caused by C1 Inhibitor Deficiency. The Journal of Allergy and Clinical Immunology, 129, 308-320.

https://doi.org/10.1016/j.jaci.2011.11.025

[8] Frank, M.M., Sergent, J.S., Kane, M.A. and Alling, D.W. (1972) Epsilon Aminocaproic Acid Therapy of Hereditary Angioneurotic Edema. A Double-Blind Study. The New England Journal of Medicine, 286, 808-812. https://doi.org/10.1056/NEJM197204132861503

[9] Prematta, M., Gibbs, J.G., Pratt, E.L., et al. (2007) Fresh Frozen Plasma for the Treatment of Hereditary Angioedema. Original Articles. Interventions, 98, 383-388. https://doi.org/10.1016/S1081-1206(10)60886-1

[10] Chinniah, N. and Katelaris, C.H. (2009) Hereditary Angioedema and Pregnancy. Australian and New Zealand Journal of Obstetrics and Gynaecology, 49, 2-5. https://doi.org/10.1111/j.1479-828X.2008.00945.x

[11] Berglund, F., Flodh, H., Lundborg, P., Prame, B. and Sannerstedt, R. (1984) Drug Use during Pregnancy and Breast-Feeding. A Classification System for Drug Information. Acta Obstetricia et Gynecologica Scandinavica, 126, 1-55. https://doi.org/10.3109/00016348409156383

[12] Aminocaproic Acid: Drug Information (2021) https://www.uptodate.com/contents/aminocaproic-acid-drug-information?search= acido\%20epsilonaminocaproico\%20drug\%20information\&source=panel search result \&selectedTitle $=1 \sim 85 \&$ usage type $=$ panel $\& \mathrm{kp}$ tab $=$ drug general\&display $r a n k=1 \# \mathrm{~F}$ $\underline{133208}$ 